\title{
“Era Uma Vez...”: O Negro No Imaginário Encantado
}

\author{
Amailton Magno Azevedo ${ }^{1}$
}

Sheila Alice Gomes da Silva ${ }^{2}$

Resumo: O presente artigo objetiva analisar as animações: "Kirikú e a Feiticeira” e "A Princesa e o Sapo", sob a luz da Lei: 10.639/03, das lutas históricas dos Movimentos Negros, buscando identificar releituras nas representações das culturas das diásporas, sociedades africanas e do continente africano, historicamente construídas a partir de um olhar ideológico eurocentrado, ou reafirmações dessas ideologias hegemônicas; a fim de contribuir com os debates e pesquisas que circundam a construção de relações étnico-raciais positivas.

Palavras-chave: Lei 10.639/03 e releituras históricas; Memórias negras; “A princesa e o sapo"; "Kirikú e a feiticeira"; Eurocentrismo-Etnocentrismo.

Abstract: This article aims to analyze the animations: "Kiriku and the Sorceress" and "The Princess and the Frog", in light of the Law: 10.639/03, the historical struggles of Black Movements, seeking to identify the re-reading reinterpretations of cultures reinterpretations of diasporas, African societies and the African continent, historically constructed from a Eurocentric ideological look, or restatements of these hegemonic ideologies, in order to contribute to the debates and research surrounding the construction of positive ethnic racial relations.

Keywords: Law 10.639/03 and historical reinterpretations; black Memories; "The Princess and the sapo"; "Kiriku and the witch"; Eurocentrism-Ethnocentrism.

\section{Introdução}

Durante muitos séculos desenvolveram-se conhecimentos e valores produtores de uma amnésia coletiva, marcados por uma ideologia cultural eurocêntrica que se autodeclarava universal e relegava diversos grupos humanos, e suas representações socioculturais e religiosas, a papéis de subalternidade na historiografia; não apenas invisibilizando-os, mas relegando-os ao não lugar e ao

1 Pós-doutorado pela Universidade do Texas em Austin; Professor do Programa de Estudos Pós Graduados em História do Departamento de História da Faculdade de Ciências Sociais da Pontifícia Universidade Católica (PUCSP); Orientador e Membro pesquisador do Centro de Estudos Culturais africanos e da Diáspora - PUC/SP. E-mail: amailtonazevedo@gmail.com

2 Mestranda em História Social - PUC/SP; Pesquisadora associada ao Centro de Estudos Culturais Africanos e da Diáspora (CECAFRO - PUC/SP). E-mail: sheilagomessilva@bol.com.br 
não ser. As representações eurocêntricas do negro e do continente africano no ocidente vão, então, reafirmar essa ideologia hegemônica e naturaliza-la, tornando-a parte do senso comum das sociedades, "O eurocentrismo situa-se de modo tão inexorável no centro de nossas vidas cotidianas, que mal percebemos sua presença." (SHOHAT e STAM, 2006, p.20). O eurocentrismo imposto pelas ideologias hegemônicas vai hierarquizar e/ou subalternizar esses outros saberes, culturas e memórias, numa lógica dominante e excludente que não as identifica como formas relevantes e compreensíveis de ser e estar no mundo, condenando-as ao esquecimento inevitável. (Santos, 2010). Esse esquecimento/apagamento do passado constituiu-se como objeto de poder que vai ao encontro das sociedades tradicionais que tem na memória seu suporte para manter suas culturas. Pois, a "memória e cultura são indissociáveis na nossa constituição enquanto seres humanos." (MONTES, 2007, p.129). Assim, mais do que evocar o tempo passado, a memória se constitui em uma ação produtora de significados para os indivíduos e sociedades.

D`Aléssio (2007) ao falar de memória e historiografia nos apresenta caminhos e descaminhos percorridos por grupos humanos afetados pelo processo de aceleração da história, apontada no final do século XX, a partir da percepção coletiva de fatos construídos em bases frágeis, marcados por uma brevidade. Diz ele ainda que além da tirania do consumismo, existe uma busca desenfreada pelo novo desonerando o passado e dando forças a uma cultura do esquecimento que tem como base pensamentos colonialistas de ideologia eurocêntrica. Em paralelo a esta realidade o autor pontua a força que os movimentos de busca identitária vão adquirindo no campo historiográfico, quando grupos sociais encontram seu sentido existencial e referencias no passado. Numa crescente necessidade de resgatar essas outras memórias, negadas e invisibilizadas pelo poder, novas linhas interpretativas incorporam-se ultrapassando dogmas, tabus e problematizando a infalibilidade de tudo que já foi produzido.

Em um movimento dialógico, onde os que eram comumente silenciados passam a serem sujeitos históricos, e suas falas e produções ganham status de fonte historiográfica, diversas proposições bibliográficas, musicais, culturais e cinematográficas são construídas como resultado desse reverberar questionador. E ainda, na ânsia de emergir, desvelar e propor uma releitura de tudo que outrora havia sido imposto como a verdade absoluta.

Propomo-nos, inicialmente, há pensarmos um pouco sobre a ideia de se fazer releitura. $\mathrm{O}$ verbete reler é composto pelo prefixo re que significa de novo, e ler que segundo o dicionário ${ }^{3}$, no

3 FERREIRA, Aurélio Buarque de Holanda. Aurélio mini: século XXI. Rio de Janeiro: Nova fronteira, 2001, p.423. 
que mais se enquadra a proposta, é: “(...) (1) Decifrar e interpretar o sentido de. (2) Perceber. (...)”. Por tanto reler significa, então, decifrar, reinterpretar o sentido, perceber novamente, reelaborar o que já se conhece e/ou já se tem uma ideia formada. Lages (2007) nos aponta para a existência de uma "cadeia infinita das leituras e releituras que atravessam a história." (IBID, p.117). Fazer uma releitura é interrogar realidades que, de modo geral, supomos conhecer, indagando, ressignificando, construindo paradoxos; subvertendo.

No Brasil não se pode falar, no tempo presente, em releitura histórica de forma relevante sem envolver-se com o universo proposto pela a Lei 10.639, promulgada no ano de 2003, pois seus movimentos predecessores fazem-na grandiosa, ao ponto de tornar sua desejada efetividade um ato revolucionário de grande representatividade para o processo de releitura da historiografia brasileira.

O processo de escravização do Negro durou cerca de três séculos no Brasil, e foi marcado principalmente por movimentos de resistência a este sistema erigido por lideranças negras que se forjaram ante as relações de poder, submissão e dominação, e suas consequências, impostas pelos luso-colonizadores aos escravizados. Estas lideranças cresceram em numero e fortificaram-se, de maneira a representarem institucionalmente os interesses desta parcela da sociedade perante $o$ Estado brasileiro, na luta e mobilização social pela efetiva conquista dos direitos sociais básicos; contra o preconceito racial, a segregação, pela inclusão educacional, a equidade de oportunidades, entre outros. Além de negarem a imagem ideológica comumente difundida no Brasil e no mundo que entendia o continente africano como uma unidade simplista e exótica, habitado por bárbaras tribos canibais, mergulhadas em lendas e misticismo; e o negro dos territórios da diáspora como fraco, incapaz, submisso à escravização.

Contra esse movimento opressor-colonizador lusitano que sempre procurou silenciar as vozes negro-africanas; “(...) negro torna-se, então, sinônimo de ser primitivo, inferior, dotado de uma mentalidade pré-lógica" (MUNANGA,1988, p.07). Os movimentos negros exigiam uma releitura da África e do Negro no Brasil que reconhecesse o continente africano como território protagonista da história da humanidade, produtor de saberes e de riquezas humanas, e o africano e seus descendentes como atores protagonistas do processo de constituição da nação brasileira. Em resposta a todo esse processo de resistência e de luta, cuja importância histórica é inestimável, foi que o Estado brasileiro promulga a Lei 10.639/03. 
A Lei $10.639 / 03^{4}$ institui a obrigatoriedade do ensino da História e Cultura Africana e Afrobrasileira em todos os espaços promotores da educação no Brasil, fazendo-se necessária uma revisão histórica e efetivas mudanças nos currículos escolares a fim de que a escola passe a pensar África. Esse movimento constitui um olhar que passa a ver o mundo para além dos valores ocidentais e identifica o negro como protagonista da construção social da história brasileira.

Neste momento histórico, aonde a lei vem coroar séculos de lutas dos movimentos negros, os espaços escolares e acadêmicos veem-se obrigados a envolver-se, a produzir, a estudar esse negro como ator de sua própria história. Toda essa obrigatoriedade que uma lei de âmbito federal implica à sociedade reverbera para além de uma revisão de velhos conceitos ou pré-conceitos, ela traz para o plano coletivo o que outrora se entendia apenas como militância de uns poucos, mas uma mudança estrutural que gera novas demandas de conhecimento. Para tanto, segundo Pereira (2011) universidades começam a abrir cursos de formação aos educadores, visando um aprofundamento do dialogo entre educadores em atuação e licenciandos. Aumenta a produção didática voltada para o assunto, entre outros, produzindo novas dizibilidades e visibilidades sobre a África e sobre o papel do negro no Brasil. - “(...) uma nação que se pensava branca (...)” -, (MUNANGA, 2008, p.48). Nessa perspectiva, Bonzatto (2011) diz que "por alinhar o Brasil com o modelo civilizatório europeu, as elites promoveram uma serie de ações para excluir o contingente da população que não correspondia a esse modelo.” (BONZATTO, 2011, p.42).

A mais de uma década da promulgação da lei ainda se tem um longo caminho a trilhar, uma luta constante para fazer com que essa releitura seja naturalizada pelos processos cognitivos do coletivo. Por isso cabe aos educadores buscarem mecanismos e instrumentos facilitadores da pratica pedagógica necessária a este processo. Instrumentos, estes que podem ser materializados como contos, músicas, danças, filmes, que nos permitam aproximar os educandos das culturas e realidades africanas e afro-brasileiras.

\section{A importância do objeto: a arte cinematográfica}

4 http://www.planalto.gov.br/ccivil_03/leis/2003/110.639.htm 
Em um tempo em que o campo da história social cresce nesse movimento de resgate de memórias de grupos étnicos e sociais, outrora excluídos da historiografia e de releituras, propomonos a discutir os olhares e concepções sobre o individuo negro e/ou afrodescendente, e sobre o continente africano e suas sociedades, trazidos a partir da arte cinematográfica.

O cinema constituiu-se numa ferramenta de múltiplas possibilidades e de alcance mundial. Seu inicio incide com o auge do imperialismo e foi predominantemente utilizado para cristalizar uma ordem social hegemônica, trazendo representações a partir da perspectiva da Europa como centro do mundo, do conhecimento, da cultura, e etc., (SHOHAT e STAM, 2006). O discurso colonizador era a única referencia para as produções cinematográficas dominantes, que por sua vez, traziam aos espectadores as civilizações classificadas como barbaras pelo eurocentrismo, assim como a africana, a partir de caricaturizações, “(...) metáforas, tropos e figuras como a animalização e a infantilização." (SHOHAT e STAM, p.31). O cinema como meio de comunicação produzia imagens, representações e valores assimilados e naturalizados por uma maioria de espectadores que sofriam com, o que tais autores vão chamar de "efeitos intelectualmente debilitantes" do legado eurocêntrico. A forte exposição visual, sonora e as narrativas envoltas por um clima mágico, permitem aos espectadores construírem no imaginário coletivo a representação de espelho do mundo. De modo geral, as pessoas não percebem a ideologia eurocêntrica que perpassa os meios de comunicação, "um tipo de mal habito epistêmico presente tanto na produção cultural dos meios de comunicação quanto na reflexão intelectual sobre essa cultura" (SHOHAT e STAM, p.33).

Shohat e Stam (2006) refletem sobre as ideologias hegemônicas que perpassam a filmografia dominante, mas também sinalizam para um momento histórico novo, um período que valoriza o policentrismo cultural, a transformação de discursos subordinados em subversivos e oposicionistas. Um tempo que se passa a pensar o outro, o nosso tempo. O cinema se constitui num espaço de conflito ideológico e desse movimento emergem novas formas de se fazer cinema, como estratégia de resistência às hegemonias, e a construção de idiomas e leituras resistentes que pronunciam outras vozes, outras narrativas denunciadoras das estruturas de poder e privilégios da minoria elitista. Esse tipo de cinema vai se contrapor ao hollywoodianismo ${ }^{5}$ e abrir caminhos para a arte cinematográfica de todos os territórios pensarem as culturas.

Tendo em vista a força da releitura como um movimento contemporâneo, analisaremos as

5 “Nos estudos cinematográficos, um outro nome para eurocentrismo é hollywoodianismo" (SHOHAT e STAM, 2006, p.61) 
animações: "Kirikú e a Feiticeira" e "A Princesa e o Sapo", ambas estão ligadas ao tema proposto, direcionam-se ao publico infanto-juvenil e têm no Brasil um grande alcance popular, estando disponíveis em locadoras, bibliotecas, sites de vídeo gratuitos, entre outros, para livre observação do publico em geral. Essa análise buscará identificar releituras ou reafirmações das ideologias eurocêntricas universalistas, nas representações das culturas das diásporas, sociedades africanas e do continente africano, apresentadas nas animações. O objetivo é contribuir com os debates e pesquisas que circundam a construção de relações étnico-raciais positivas.

\section{Kiriku e a Feiticeira}

A animação denominada: "Kirikú e a feiticeira", originalmente: "Kirikou et la sorcièr" (em francês), tem como roteirista e diretor: Michel Ocelot, animador francês, recebedor de importantes prêmios da animação internacional e que viveu durante a infância na Guiné, pais do continente africano $^{6}$. A trilha sonora da animação é assinada por Youssou N`Dour - Cultfilmes França/Bélgica que compôs todas as canções com instrumentos tradicionais do continente como: balafon, ritti, coraxalam, tokho, sabaar e o belon?

A animação foi lançada mundialmente no ano de 1998, tem 1 h10 minutos de duração. $\mathrm{O}$ enredo é uma lenda africana que se constrói a partir de um menino que antes mesmo de nascer já demonstrava no ventre de sua mãe uma notabilidade impar. Esforçando-se nasce sozinho, corta o próprio cordão umbilical e, para apresentar-se ao mundo, se autonomeia Kirikú,

Esteticamente é a personificação do anti-herói eurocêntrico, quando, primeiramente, é apresentado como uma criança. Nos contos de fada e histórias de heróis, no geral, estes são sempre adultos, dotados de força e/ou poderes especiais. Kirikú é doce, tranquilo e pacificador; além de muito pequeno e negro. Mesmo com todas as características citadas que já nos trazem uma contraposição à imagem heroica que habita o imaginário popular, a construção de um herói negro nos permite perceber a primeira releitura.

No livro Negritude: Usos e Costumes (MUNANGA, 1988) o autor vai problematizar a imagem negativa que a historiografia eurocêntrica construiu e perpetuou sobre o negro de modo universal, como: "retardado, perverso, ladrão" (MUNANGA, 1988, p. 13). Segunda Munanga

6 Informações retiradas do Internet Movie Database, fonte de dados on line, originalmente britânica, mantido atualmente pela Amazon.com. http://www.imdb.com/name/nm0643664/, acessado em 05/03/2014.

7 Informações retiradas do DVD da animação "Kirikú e a feiticeira". 
(1988), essa ideologia que era imposta ao indivíduo negro como inescapável conduziu-o a uma condição de eterno perdedor. A animação vai de encontro com esse universo, e apresenta um herói negro cheio de seus atos de coragem, bondade, autonomia e benevolência.

Diferente de uma visão estereotipada a animação faz o elogio à tradição, numa visão que vai de encontro com o eurocentrismo, que "impõe uma narrativa linear, que encerra os povos das sociedades tradicionais como prisioneiros de um passado inerte incapazes de ação e mudança." (SHOHAT e STAM, 2006, p.418), a partir da representação do cotidiano de uma comunidade senegalense, habitante do continente africano, e suas relações com a natureza, o modo de vestir-se, a organização social, a relação com o sagrado, à musicalidade; trazendo, assim, outros possíveis caminhos e sentidos de existência no mundo.

Nas imagens da comunidade, denominada aldeia na animação, é possível percebe-la circundada por árvores Baobás; todos os personagens estão caracterizados com penteados e roupas tradicionalmente africanas. Outras cenas trazem a leveza das ações cotidianas, como: (a) a mãe de Kirikú varrendo sua cabana com uma vassoura tradicional (monte de palha amarrada sem cabo), (b) Kirikú dormindo em uma esteira, mulheres cozinhando e batendo alimentos no pilão.

O enredo da animação traz o núcleo da maldade e dominação materializado por karabá, a feiticeira, que esta sempre banhada em joias e com uma vestimenta que sugestiona superioridade diante da simplicidade nua de Kirikú. Karabá se diz autora do feitiço que escraviza e subjuga os habitantes da comunidade de Kirikú aos seus mandos e desmandos, e faz todos acreditarem que devorou todos os homens da comunidade, inclusive o pai de Kirikú, seus pais e tantos outros, situações que acabam por aproximar esses dois personagens dentro da história.

Muitas vezes desacreditado pela comunidade por ser criança e pelo seu tamanho (minúsculo), Kirikú nos traz a imagem de um negro que resiste ao preconceito, luta por seus objetivos, e é resiliente. Por vezes, salva as crianças da comunidade das armações de Karabá, e com isso é louvado com danças e cantos por todos, "Kirikú é pequeno, mas é bem valente" “ele é pequeno e tem seu valor", enaltecendo sua bravura e heroísmo.

O pequeno Kirikú além de atos heroicos traz ao espectador reflexões sobre o mundo em que vivemos, mostrando a todos um pouco da sabedoria africana no tecer as relações humanas. Em uma das cenas, em que mostra um dialogo entre Kirikú e sua mãe, ele se queixa da maldade das pessoas referindo-se a Karabá. Como resposta, a mãe lhe diz que a feiticeira não era a única má, lembrando 
o filho que a maldade é algo coletivo. Então, Kirikú lembra-se que apesar de ter salvado tantas vezes as crianças ainda não era tratado bem por elas, mas mesmo assim ele diz a ela que se tratando de uma comparação entre os dois tipos de maldade, com certeza, Karabá era a mais malvada. Em resposta as colocações do filho, a mãe de Kirikú problematiza sua afirmação questionando-o e a todos nós, se a feiticeira era a mais malvada ou a era a pessoa que tinha mais poder? Questionamento que reflete um pouco da sabedoria africana, sobre o caráter dos homens diante do poder.

Influenciados pela cultura eurocêntrica geralmente dividimos o mundo em duas vertentes principais: a do vencido - perdedor e a do vencedor, o que se estende a literatura, ao cinema, teatro, novelas, entre outros. Torcemos para que os perdedores sejam, necessariamente, os malfeitores, acreditando que a morte é o único possível e maior castigo que o mocinho e/ou herói deve empreender contra os personagens que representam a ameaça.

Kirikú nos mostra um caráter reconstrutor ideológico quando inusitadamente busca primeiro tentar entender a razão de toda a maldade do opressor e não pensa em simplesmente mata-lo para livrar-se do problema. Diferente disso Kirikú recorre a um sábio (seu avô) - valorizando o conhecimento do ancião/idoso/aquele que já muito viveu - não para fazer de Karabá a perdedora, mas fazer todos os participantes da história vencedores. Trazendo-nos a percepção do coletivo, a importância do perdão, altruísmo e da astúcia; características tão raras de serem percebidas em nossa sociedade contemporânea. Quando Kirikú busca o sábio da comunidade para entender o que acontece, a animação nos mostra a supervalorização do passado no presente. Traz-nos uma cultura que não apaga ou desvaloriza o passado em detrimento do presente, mas propõe um andar junto, um reconhecimento do ancião e/ou do que foi como base do que é.

Kirikú descobre o real motivo de tanta maldade demonstrada pela feiticeira; um espinho na carne de Karabá, além disso, seu avô revela a ele que quanto mais as pessoas têm medo dela, mais poderosa ela fica. O herói Kirikú então percebe que ele não veria teme-la, mas antes, benevolentemente liberta-la de uma maldade que se apoderara dela. Kirikú retira o espinho, e livraa da prisão que se tornará o seu poder.

A animação nos traz outra possibilidade de se tratar o vilão, olhando para o ser humano que há por trás da maldade. A feiticeira livre da maldade destrói o feitiço; e com isso, não apenas a feiticeira ou Kirikú, mas todos, todos ganham, todos saem vencedores. 
Todos na comunidade passam cantar e dançar: "Kirikú é o melhor em nós", mostrando ao espectador que as aparências enganam uma das várias ideias trabalhadas no filme.

Com Kirikú é possível se abrir para outras possibilidades, uma substituição do: "Eles foram felizes para sempre", pelo "E todos foram felizes para sempre." A partir de um herói que contraria as noções universalistas e estereotipadas desse personagem, e que outrora estaria fadado a figuração e sátira, "Kirikú e a Feiticeira" propõe outros olhares, outros modos de ser e estar no mundo, nos propõe pensar a não ocidentalização do mundo, e nos faz pensar África.

\section{A princesa e o sapo}

Em outro exercício analítico trazemos a animação: "A princesa e o sapo", lançada pelos estúdios Disney no ano de 2009, sob a chamada de ser a "primeira princesa negra da Disney". De modo geral representaria, então, a abertura dos estúdios de maior representatividade na história das animações no mundo para as histórias da África e sua diáspora. Mesmo assim o enredo da animação é baseado no conto do Príncipe Sapo $^{8}$ de autoria dos Irmãos Grimm, que eram de nacionalidade alemã e atingiram notoriedade como escritores de fabulas infantis. Isso nos faz questionar: como uma animação baseada num conto de origem alemã pode trazer ao público o universo de permanências e rupturas da Diáspora africana, especificamente, na América do norte? Permitimonos, então, a partir dos conceitos trazidos na introdução do artigo sobre a universalidade empreendida pelo eurocentrismo na escrita da historiografia mundial, perceber esse fato estruturador da animação, na proposta do texto, como reafirmação.

As cenas são ambientadas na cidade de Nova Orleans da década de 1920, berço do jazz norte americano, outrora, grande polo de trafico de negros vindos da parte Ocidental do continente africano para serem escravizados. Apresenta, ineditamente, ao público muitos personagens negros e/ou afro-americanos, dentre eles direcionaremos nossa análise, principalmente, para três: Tiana (a princesa), Naveen (o príncipe sapo) e Dr. Facilier (o bruxo).

Como todo conto de fadas a animação traz, de forma bem definida, o núcleo dos mocinhos e dos vilões. A princesa Tiana, que no começo da animação é apenas uma plebeia pobre, é a primeira personagem que nos ateremos e que faz parte do núcleo dos mocinhos. Tiana tem a pele negra, mas apresenta um fenótipo distante dos traços negroides comuns a população afrodescendente. Seus

8 Disponível em: http://www.botucatu.sp.gov.br/eventos/2007/conthistorias/bauhistorias/contosinfantis.pdf , acessado em $10 / 02 / 2014$. 
cabelos não são crespos e nem trançados, seus lábios são cuidadosamente desenhados para não estarem nem grossos demais e nem muito finos, além de corpo seguir os padrões eurocêntricos de beleza associada, especificamente, à magreza.

Tiana é filha de uma costureira negra que presta serviços na casa de uma família branca, rica, e que tem uma filha, Charlotte, que convive com Tiana nas visitas que a mãe faz para tirar as medidas de roupas da menina. Quando Tiana e sua mãe saem da casa de Charlotte, depois de mais uma tiragem de medidas para um novo vestido, é possível que observemos na sequência de imagens que se seguem durante a viagem de volta para a casa de Tiana a segregação urbano-territorial que os negros estavam confinados em Nova Orleans. Numa viagem de bonde são perceptíveis as mudanças estruturais que se mostram ao sair de um bairro "nobre" para a periferia. De mansões bem iluminadas e ruas arborizadas para casebres velhos, pequenos e rústicos. O que nos permite classificar essa cena do filme, como um dos momentos promotores de releitura da historiografia eurocêntrica, que não admite as violências perpetradas contra a população africana e afrodescendente nos territórios da diáspora.

Motivada desde a infância pela ideologia meritocratica propagada pelo falecido pai e pelos sonhos dele de montar um restaurante na cidade onde moravam, Tiana acumula funções e economiza todo o dinheiro que pode para realizá-lo. A ideologia meritocracia, sinalizada por Shohat e Stam (2006) como a hiper valorização das conquistas pessoas e da contra vitimização, que foi imputada aos negros na historiografia eurocêntrica e que representa de modo latu a reafirmação dos conceitos universalistas, é expressa diversas vezes em falas de Tiana; como: “o único jeito de conseguir algo nesse mundo é trabalhando muito!"; "vou me esforçar para ter o meu lugar ao sol”; e "se você der o seu melhor atraíra o melhor para você".

$\mathrm{Na}$ ânsia de completar o dinheiro que usaria para comprar um galpão, que serviria como sede do sonhado restaurante, Tiana vai trabalhar na festa de Charlotte, um baile à fantasia, que se inicia e segue com um tango, apesar de estarem na capital do Jazz. O que nos sugere, dentro desse universo proposto pela animação, uma reafirmação dessa segregação espacial e agora musical entre negros e brancos, também em Nova Orleans. O Jazz em diversas cenas é o ritmo que embala o cotidiano da cidade e dos territórios negros, e o tango, por exemplo, um ritmo, nesse caso, mais próximo da elite.

Em uma das cenas que mostra Tiana, ainda criança, e seu pai em casa preparando uma sopa, 
a história nos trás um senso de comunidade, do acolhimento, da união, da coletividade africana. O pai de Tiana a questiona, retoricamente, sobre o que a comida tem de bom, e responde dizendo: "ela reúne as pessoas de todas as classes sociais, da uma sensação boa aqui (apontando para a barriga) e põe felicidade no rosto delas". Ao fazer a sopa Pai e Filha distribuem para todos da comunidade, num ato coletivo de comensalidade, onde cada um traz mais alguma coisa e juntos colocam em prática a partilha e/ou o ditado popular: "Quando um tem todos tem”. Essa coletividade africana é um dos elementos que nos permitem refletir sobre o pensamento filosófico africano. A representação da família ocidental é composta por um núcleo principal: pai, mãe e filhos; já nas sociedades tradicionais o conceito de família é estendido ou, como denominado por Serrano e Waldman (2007): "famílias extensas", onde todos os membros da comunidade são mães, pais e irmãos. A responsabilidade de um é para com todos e a responsabilidade de todos é para com cada um; é um eu comunitário. Esses valores familiares permanecem resistindo a ideologia hegemônica, não se dissolveram e mantem o equilíbrio das comunidades tradicionais que tem como suporte fundamental o grupo familiar. Um conceito que retrata uma experiência histórica, porque produz uma espécie de estrutura social de sustentação a partir de uma profunda base solidaria entre os indivíduos. Essa experiência social vai desenvolver nos indivíduos do grupo uma consciência de pertencimento, laços de solidariedade que segundo Serrano e Waldman (2007) impactaram e/ou influenciaram a dinâmica das diásporas e a formação dos territórios americanos.

Há ainda uma cena que nos chama a atenção de maneira especial por unir sons e imagens na transmissão das idéias. Quando Tiana ao cair em cima da mesa das guloseimas que servia na festa suja a sua fantasia, é levada por Charlotte para trocar-se, e sai com um vestido típico das princesas européias dos contos de fada mais populares, de luvas, salto alto e com um vestido longo brilhante. Assim que Charlotte a vê vestida dessa maneira, a cena fica a meia luz com foco especificamente em Tiana, além da trilha sonora também sugerir surpresa e fascínio. Charlotte fica boquiaberta dizendo a Tiana que estava mais bonita que as flores da primavera. Ao aproximar-se do universo de beleza européia através das roupas e acessórios, ela fica deslumbrante, ela chama a atenção pela beleza que em suas roupas normais, com sua beleza naturalmente negra não reconheciam.

Quando Tiana finalmente consegue todo o dinheiro para dar entrada na compra do galpão que almeja, tem seu primeiro momento musical na animação, que será a materializado numa idealização do seu sucesso a frente do restaurante. Nesse sonho ela esta usando um vestido de branco, modelo dos anos 20, com seus cabelos lisos num corte chanel; o que nos permite associar 
sucesso a embranquecimento. As roupas mudam, os traços mudam, quanto ao próximo do sucesso mais próxima da branquitude ela será apresentada pela animação, numa reafirmação dos valores eurocêntricos.

O outro personagem que nos propomos a analisar é o príncipe Naveem, da Maldonia, que chega a cidade procurando um casamento com uma garota rica, a fim de sair da falência financeira que se encontra. É apresentado, diferentemente de todos os outros príncipes conhecidos dos contos de fadas produzidos pela Disney, com características mais próximas dos vilões, como: malandro, ganancioso, mulherengo e aproveitador. A própria Tiana (personagem principal da animação) no inicio da animação o define como: “inútil, preguiçoso e muito abusado!”. Ele é negro, e numa inversão de valores, nunca antes pontuada em animações, tem o mordomo branco. Apesar de todas as cenas mostrarem relações raciais, entre negros e brancos, tranqüilas e boa convivência, Naveem, negro, maltrata de maneira sarcástica o seu mordomo, branco. E assim como Tiana, tem suas características fenotípicas distanciadas dos traços negróides.

O núcleo da maldade e/ou do vilão é composto pelo Dr. Facilier (denominado feiticeiro) ou Homem Sombra, praticante de Vodum, tradição religiosa teísta-animista baseada nos ancestrais, tem suas raízes primarias nas sociedades Ewe-Fon da África Ocidental (Benin). Apresentado com um caráter negativo, invejoso e ganancioso, tem sua primeira aparição na animação costurada a uma música que nos traz um olhar restrito e universalista sobre suas praticas de Vodum, como: “Tem magia boa e má", trazendo na palavra má um close ao personagem, quando o mesmo jogava cartas para um senhor branco na cidade. Outra parte da musica, é: "Consiga o que quer e depois perca tudo..." classificando o Vodum uma prática mentirosa e enganadora. Numa outra cena Facilier promete almas aflitas as divindades do Vodum, sugestionando uma demonização da prática. Tiana (protagonista) refere-se ao Vodum como: "magia negra" numa conotação negativa. O filme, de modo geral, representa o Vodum sob as lentes disciplinares da ideologia hegemônica eurocêntrica que segundo Shohat e Stam (2006) traz a Europa numa perspectiva central no mundo do conhecimento, da cultura, entre outros.

O personagem do "bruxo" tem em suas características fenotípicas com uma maior incidência de traços negróides, como: lábios grossos e nariz não afunilado, o que não encontramos nos personagens do núcleo dos mocinhos. O que nos permitiu associar a uma linha da cor, onde a bondade esta associada ao embranquecimento ou aproximação da beleza eurocêntrica, e a maldade ao distanciamento desta e/ou enegrecimento. 
A história da animação, de modo geral, é simples e continua de maneira copiosa os contos de fadas já lançados pelos estúdios em outros momentos. A menina pobre que tem um brilho próprio, uma bondade exacerbada, e uma vontade de melhorar de vida, no que tange sua condição social. Dr. Facilier, o feiticeiro, quer usar o príncipe falido, Naveem, para casar com a rica Charlotte, e conseguir dominar a cidade com a fortuna que herdaria. Acaba então enganando o príncipe e transformando-o em um sapo, e fazendo seu maltratado mordomo tomar seu lugar fisicamente, com a magia. Para desfazer o feitiço colocado em Naveen era preciso que ele convencesse uma princesa a lhe beijar, e Tiana disposta a ajudar o beijou, mas diferente do que pensava, por ela não ser uma princesa, o feitiço também a atinge e ela se torna uma rã. Juntos os dois terão que encontrar um meio de desfazer o encanto.

Como todo conto de fadas também passa uma mensagem: o príncipe - aprende que o dinheiro não é a coisa mais importante para a vida do homem, e que o amor e o carinho de seus amigos e da mulher que se apaixonou valem muito mais; Tiana - percebe o quanto é especial e que tem capacidades para além do que imaginava; Dr. Facilier - morre na reafirmação recorrente dos contos de fada da Disney de que o fim de tudo que é mal é morrer, a morte como um castigo. O fim da animação não traz nenhum argumento inédito, eles se casam e vivem felizes para sempre. Esse “eles" enquadrando apenas o núcleo dos mocinhos, claro!

\section{Considerações Finais}

A partir de movimentos questionadores das narrativas hegemônicas, releituras emergem como contra narrativas, num intuito de fazer ouvir vozes, outrora, silenciadas. São mulheres, crianças, pobres, trabalhadores, nordestinos, migrantes, entre tantos outros, e negros.

Sociedades africanas e afrodescendentes foram submetidos a um processo de desumanização na história mundial, pelo sistema de dominação e escravidão empreendidos por brancos "colonizadores". Até hoje não é difícil identificar práticas discriminatórias contra o individuo negro nas diversas sociedades, e em especial, no Brasil. Um país que tem sua história marcada pela busca de uma identidade que "higienizasse" e/ou promovesse a eugenia, e o branqueamento da nação. Perpetuando no imaginário coletivo a necessidade de excluir o negro das paisagens urbanas, das empresas, das escolas, enfim, da nação como um todo.

A partir de lutas individuais e de movimentos de resistência organizados, torna-se 
possível propor que pensemos um Brasil Negro. A partir desses olhares ampliados educadores e a sociedade, no geral, passam a demandar novos meios de se repensar a África e o negro. Sendo assim, animações como as que analisamos: "A princesa e o Sapo" e "Kirikú e a Feiticeira”, acabam sendo usados por educadores e pela sociedade como instrumentos promotores de releitura, sem que haja uma real análise da história e das cenas apresentadas. Há de se refletir sobre tais questões que no lugar - comum da filmografia é também uma construção ideológica que pode trazer uma nova perspectiva do racismo, da discriminação e do preconceito nas novas relações de poder postas no mundo.

Em virtude dos fatos mencionados e das análises empreendidas no corpo do artigo entendemos que cada animação traz um olhar diferenciado sobre o continente África e suas sociedades, ou sobre o afrodescendente. Proporcionando ao espectador possibilidades de perceber o universo negro-africano, hora reafirmando as narrativas hegemônicas, hora questionando e/ou promovendo releituras.

A partir da análise de cada filme foi possível concluir que de modo geral o filme "Kirikú e a Feiticeira" reúne elementos que trazem ao espectador um conjunto de novos olhares sobre o que as narrativas hegemônicas propagaram contra o negro e/ou afrodescente e contra a África. Partindo das belas paisagens no fundo das cenas, a sabedoria dos indivíduos, o retrato do cotidiano de uma África não estereotipada, o espirito de luta e resistência e por fim o herói negro. Propondo ao espectador pensar o mundo para além do ocidente, aparentando ser uma animação para o publico infantil, mas tratando de assuntos que interessam todas as gerações havidas por reconhecer-se e identificar-se em filmografias.

A animação se desenrola em meio aos valores africanos de coletividade, alegria, suas relações com a natureza, entre outros, trazendo mensagens de perdão, altruísmo, coragem e resistência.

Com relação à segunda animação analisada: "A princesa e o sapo", entendemos que apesar de apresentar algumas cenas que nos permitem identificar questões de grande importância, como a segregação urbano-espacial do negro em Nova Orleans e das áfricas da diáspora, ainda sim a animação não traz representativamente uma releitura das narrativas hegemônicas e/ou eurocêntricas, e o discurso do colonizador perpassa muitas de suas cenas. O filme, de modo geral, traz um olhar míope sobre diversos assuntos, reafirmando as vozes dominadoras de uma 
historiografia que silencia, classifica e exclui o que caracteriza diferente. Apesar da promessa que envolve sua chamada de lançamento: "A primeira princesa negra da Disney" a animação não da conta de todos os significados que esta máxima traz consigo.

Contudo acreditamos ser imprescindível que educadores, pais, entre outros, que tenham contato com animações como estas que analisamos, desempenhem um olhar critico na busca de realmente promover uma mudança em nossa sociedade, a partir de releituras que fidedignamente pautem-se em discursos contra hegemônicos, a fim de que verdadeiramente promovamos as relações Étnico-raciais positivas, o real objetivo da lei 10.639/03 e dos movimentos negros.

\section{Referências Bibliográficas}

BONZATTO, Eduardo Antonio. Aspectos da História da África, da Diáspora Africana e da Escravidão: sob a Perspectiva do Poder Eurocêntrico. São Paulo: Ícone, 2011.

D`Aléssio, Márcia. Memória e historiografia: a experiência com históriadores franceses. In Miranda, Danilo Santos de. (Org). Memória e Cultura: A importância da memória na formação cultural humana. São Paulo: SESC SP, 2007

LAGES, Suzana Kampff. Literatura e memória - caminhos e descaminhos. In Miranda, Danilo Santos de. (Org). Memória e Cultura: A importância da memória na formação cultural humana. São Paulo: SESC SP, 2007.

MUNANGA, Kabengele. Negritude: Usos e sentidos. 2. ed. São Paulo: Ática, 1988.

MUNANGA, Kabengele. Rediscutindo a mestiçagem no Brasil: Identidade Nacional versus Identidade Negra. 3. ed. Belo Horizonte: Autêntica, 2008.

PEREIRA, Amilcar Araújo. A pesquisa e o Ensino de História da África a partir da Lei 10.639/03. In: A Universidade e a formação para o Ensino de história e Cultura africana e indígena. Editora da Prefeitura Municipal de São Paulo: São Paulo, 2009.

SANTOS, Boaventura de Sousa. Para além do pensamento Abissal: das linhas globais a uma ecologia de saberes. In: ; MENESES, Maria Paula. (Orgs.) Epistemologias do Sul. São Paulo: Cortez, 2010.

SERRANO, Carlos; Waldman, Maurício. Memória d' África: a temática africana em sala de aula. Ed. Cortez: São Paulo, 2007.

SHOHAT, Ella e STAM, Roberto. Critica da imagem eurocêntrica: multiculturalismo e representação, trad: Marcos Soares, São Paulo: Cosacnaif, 2006. 